\title{
Implementation of the Solid Waste Management of Barangays in a Highly Urbanized City
}

\author{
Joedcel M. Go ${ }^{1}$ and Merlita V. Caelian ${ }^{2}$ \\ ${ }^{1}$ Department of Education-Negros Occidental Schools Division, Bacolod City, Philippines ${ }^{2}$ University \\ of Negros Occidental-Recoletos, Bacolod City, Philippines
}

\begin{tabular}{l} 
Article history \\
Submitted: 29 October 2020 \\
Revised: 4 November 2020 \\
Accepted: 16 November 2020 \\
\hline Keywords \\
Public Administration \\
Ecological Solid Waste Man- \\
agement \\
Implementation \\
Barangays \\
Descriptive-Comparative \\
Highly Urbanized City \\
Philippines
\end{tabular}

city.
Introduction. The present alarming environmental world crisis is the uncontrolled generation and illegal dumping of solid waste (SW) that poses great harm to public health and the environment (Madrigal \& Oracion, 2017; Ali \& Sion, 2014). Poor waste management may cause air, water, and soil contamination. The Ecological Solid Waste Management Act (ESWMA) or Republic Act 9003 (RA 9003) had been in place for several years. However, its implementation was a challenge for every LGU, including in a highly urbanized city. Hence, the paper examined the level of implementation of the provisions and enforcement of prohibited acts on ESWMA of barangays as assessed by community leaders as a whole and according to their geographical location and income. Also, it explores the challenges encountered by the barangays and the recommendations of the community leaders in the implementation of RA 9003 and the local ordinance enacted by the

\begin{abstract}
Methods. The study utilized descriptive and comparative methods to interpret the level of implementation and enforcement of the prohibited acts of ESWM of the 61 barangays. There are 261 respondents who are purok leaders selected through stratified random sampling. Each barangay is represented by area leaders chosen through a fishbowl technique. A validated and reliability-tested researcher-made questionnaire anchored on provisions of RA7160 or the Local Government Code of the Philippines and DAO No. 2001-34 of the Department of Environment and Natural Resources (DENR) and MC No. 2018-38 of the Department of Interior and Local Government (DILG). To analyze the data, the Mean and Standard Deviation, frequency count, and distribution percentage were utilized in the descriptive problems, while Mann Whitney $\mathrm{U}$ and Kruskal-Wallis $\mathrm{H}$ test were used for comparative problems.
\end{abstract}

Results. The findings of the study revealed that the level of implementation of the provisions and enforcement of prohibited acts of ESWMA in barangays of a highly urbanized city is on a moderate level. Implementation in sub-urban barangays was rated a bit higher than urban barangays, although both are interpreted moderate. Out of the 16 provisions that should be implemented by the barangays, nine provisions were rated low. In contrast, the other provisions scored as moderate. In terms of income, barangays with low income were rated higher while the lowest-rated barangays are those with medium income, both interpreted moderate. High-income barangays were also rated moderate in the implementation of the SWM. The level of enforcement of prohibited acts is generally moderate, which means that prohibited acts are enforced only sometimes. There were nine provisions for the enforcement of prohibited acts devolved to the barangays. Results revealed that four items were rated low/seldom enforced. Four items were rated moderate/enforced sometimes, and one prohibited act was assessed as good/enforced most of the time. As to geographic location, the enforcement of prohibited acts by sub-urban barangays was rated a bit higher than urban barangays. Both interpreted moderate. As to income, high-income barangays were rated moderate slightly higher than ratings of medium and low-income barangays. There is no significant difference in the level of implementation of the provisions and enforcement of prohibited acts of RA 9003 when barangays are grouped according to geographical location and income. The two topmost challenges encountered in implementing the provisions and enforcement of prohibited acts of ESWMA are insufficient financial allocation at the purok level (Srivastava et al., 2014) and lack of 
technical expertise in recycling and composting (Almazan \& Vargas, 2016). Recommendations include "conduct of training to increase awareness" (Madrigal and Oracion, 2017) and enactment of a barangay ordinance prohibiting the single-use of plastic bags.

Conclusion. Waste management has taken the back seat in local governance. The complacency of the local officials could be attributed to the lack of awareness and understanding of the barangay officials and residents of the repercussions of improper waste management, not discounting the lack of close monitoring of performance from national agencies and the LGU. Implementation and enforcement of the provisions and enforcement of prohibited acts under RA 9003 is an initiative to reduce waste. Its guidelines should be promoted extensively in different media platforms to promote citizen's participation.

Practical Value of the Paper. The study significantly contributes to the few existing literature on SWM implementation and enforcement of prohibited acts at the barangay level. The results of the study provided baseline information for an enhanced barangay solid waste management program.

\section{References}

Almazan, C. V., \& Vargas, D. (2016). Sustainable Solid Waste Management System: Barangay Bayog, Los Baños, Laguna. CLSU International Journal of Science \& Technology (2016), 1(2), 15-25.

Ali, N. E., \& Sion, H. C. (2014). Solid waste management in Asian countries: a review of solid waste minimization (3'r) towards low carbon. In IOP Conference Series: Earth and Environmental Science (Vol. 18, No. 1, p. 012152). IOP Publishing.

Anestina, A. I., Adetola, A., \& Odafe, I. B. (2014). Performance assessment of solid waste management following private partnership operations in Lagos State, Nigeria. Journal of Waste Management, 2014.

Bagolong, S. (2016, March). Revisiting the Implementation of Republic Act 9003 or the Ecological Solid Waste Management Act of 2000: A Community Participation in Davao City. Presented during the 8th National Social Science Congress held in June (pp. 15-17).

Boateng, S., Amoako, P., Appiah, D. O., Poku, A. A., \& Garsonu, E. K. (2016). Comparative analysis of households solid waste management in rural and urban Ghana. Journal of Environmental and Public Health, 2016.

Johari, A., Alkali, H., Hashim, H., Ahmed, S. I., \& Mat, R. (2014). Municipal solid waste management and potential revenue from recycling in Malaysia. Modern Applied Science, 8(4), 37.

Madrigal, D. V., \& Oracion, E. G. (2017). Solid Waste Management Awareness, Attitude, and Practices in a Philippine Catholic Higher Education Institution. Recoletos Multidisciplinary Research Journal, 5(2).

Punongbayan, C. M., Abu, S. P., Arago, M. P., Caponpon, M. G., Marie, A., Geron, C., \& Manzano, A. (2014). Waste management practices of an educational institution. Asia Pacific Journal of Education Arts and Sciences, 1(4), 15-20.

Srivastava, V., Ismail, S. A., Singh, P., \& Singh, R. P. (2015). Urban solid waste management in the developing world with an emphasis on India: challenges and opportunities. Reviews in Environmental Science and Bio/ Technology, 14(2), 317-337.

Vivar, P. C., Salvador, P., \& Abocejo, F. (2015). Village-level solid waste management in Lahug, Cebu City, Philippines. Countryside Development Research Journal, 3(01), 96-108.

\section{Correspondence:}

Joedcel M. Go [egrmgo@yahoo.com]

https://orcid.org/0000-0001-9966-6811 